\title{
Macromolecular Branch
}

National Cancer Institute

\section{Source}

National Cancer Institute. Macromolecular Branch. NCI Thesaurus. Code C63925.

An oligomeric or polymeric construct that extends from the parent macromolecule. 